\title{
Superação da dormência em sementes de visgueiro- do-igapó (Parkia discolor)
}

\author{
Sammy Aquino PEREIRA ${ }^{1}$, Sidney Alberto do Nascimento FERREIRA ${ }^{2}$ \\ RESUMO \\ O presente trabalho teve como objetivo avaliar os efeitos da aplicação de tratamentos pré-germinativos de escarificação mecânica, \\ bem como pré-tratamentos com calor, sobre a germinação de sementes de visgueiro-do-igapó (Parkia discolor Spruce ex Benth.). \\ No primeiro experimento, sob delineamento inteiramente ao acaso, com quatro repetiçóes, foram avaliados os pré-tratamentos: \\ testemunha (sem pré-tratamento); desponte no lado distal; desponte no lado proximal; desponte nos lados distal e proximal; \\ lixamento no lado distal; lixamento no lado proximal; lixamento nos lados distal e proximal; perfuração do tegumento com \\ ferro-de-solda; e perfuração com pirógrafo. No segundo experimento, foi adotado o delineamento inteiramente casualizado, \\ em esquema fatorial 2 (calor: seco e úmido) x 4 (temperatura: $40^{\circ} \mathrm{C}, 50^{\circ} \mathrm{C}, 60^{\circ} \mathrm{C} \mathrm{e} 70^{\circ} \mathrm{C}$ ) x 5 (período de condicionamento: 6 , \\ 16, 24, 30 e 48 horas), com três repetiçóes. O desponte ou lixamento das sementes na porção proximal e porçóes proximal e \\ distal possibilitaram uma embebição mais rápida (143-163\%, aos três dias e meio) e, conseqüentemente, melhores resultados \\ de germinação (98-100\%, aos quatro dias), do índice de velocidade de germinação $(1,351-1,460)$ e do tempo médio de \\ germinação (3 dias). Os pré-tratamentos com calor (úmido e seco), sob diferentes temperaturas, e por vários períodos de \\ condicionamento não superaram a dormência de sementes de $P$. discolor.
}

PALAVRAS-CHAVE: Impermeabilidade do tegumento, tratamento pré-germinativo, germinação.

\section{Overcoming seed dormancy in visgueiro-of-the-igapó (Parkia discolor)}

\begin{abstract}
This study aimed to evaluate the effects of pregerminative mechanical scarification treatments, as well as heat pre-treatments on the germination of visgueiro-of-the-igapó (Parkia discolor Spruce ex Benth.) seeds. The first experiment, with a completely randomized design and four repetitions, evaluated these pre-treatments: control (without pre-treatment); clipping at the distal portion; clipping at the proximal portion (hilum); clipping at the proximal and distal portions; scraping at the distal portion; scraping at the proximal portion; scraping at the proximal and distal portions; perforation of the husk with a soldering-iron; and perforation by pyrography. In the second experiment, with a completely randomized design and factorial 2 (heat: dry and wet) $\times 4$ (temperature: $40^{\circ} \mathrm{C}, 50^{\circ} \mathrm{C}, 60^{\circ} \mathrm{C}$ and $70^{\circ} \mathrm{C}$ ) $\times 5$ (period of conditioning: 6, 16, 24, 30 and 48 hours), with three repetitions. The clipping or scraping of the seeds in the proximal portion and proximal and distal portions allowed faster imbibition of the seeds (143-163\% in three days and half), and consequently, better germination (98-100\% in four days), germination speed rate $(1,351-1,460)$ and average time of germination (3 days). The pre-treatment with heat (wet and dry), under different temperatures and different conditioning periods did not overcome the dormancy of $P$. discolor seeds.
\end{abstract}

KEYWORDS: Impermeability of seed-coat, pregerminative treatment, germination.

1 INPA - CFT, caixa postal 478, 69011 - 970, Manaus, AM. E-mail: sammy.aquino@gmail.com

2 INPA - CPCA, caixa postal 478, 69011 - 970, Manaus, AM. E-mail: sanf@inpa.gov.br 


\section{INTRODUÇÃO}

Parkia discolor Spruce ex Benth. (Fabaceae, Mimosoideae), denominada popularmente como visgueiro-do-igapó, araratucupi e faveira, é uma espécie Amazônica que ocorre em solo arenoso de floresta sazonalmente inundada por rio de água preta, área também conhecida como igapó (Hopkins, 1986). É uma espécie de uso na medicina popular, tem importância ecológica e possui potencial econômico (Hopkins, 1986; Cavada et al., 2000; Souza e Silva, 2002). A árvore alcança 15 $m$ de altura e possui folhas compostas; a inflorescência é vistosa, do tipo capítulo, e contem um eixo horizontal ascendente, que se projeta além da folhagem; seus frutos, do tipo vagem, são oblongos, coriáceas, indeiscentes, e possuem entre 9-15 sementes (Hopkins, 1986). Estas apresentam dormência, devido à impermeabilidade do tegumento, e toleram longos períodos de submersão em água, bem como de exposição a condiçóes ambientes, com pequeno comprometimento da sua viabilidade (Coutinho e Struffaldi, 1971).

Para várias espécies da família das Leguminosas, especialmente aquelas que possuem sementes que apresentam dormência do tipo tegumentar (relacionada ao tegumento duro e impermeável), muitos trabalhos têm priorizado a investigação experimental de tratamentos pré-germinativos que possibilitem otimização da germinação das sementes (Souza et al., 2000). A maioria dos métodos propostos para superar a dormência dessas espécies baseia-se em técnicas que promovem danos ou rupturas na camada que reveste a semente para a absorção de água, pois, é com a embebição que se inicia o processo de germinação, onde a semente necessita alcançar um nível adequado de hidrataçáo, permitindo a reativação dos processos metabólicos. Como existe grande variabilidade entre indivíduos e entre sementes de uma mesma árvore e, até mesmo, de um mesmo lote de semente, há necessidade de se estabelecer métodos adequados para se obter germinação uniforme em cada uma das situaçôes (Souza e Silva, 1998).

Os trabalhos de germinação com sementes das espécies do gênero Parkia destacam a impermeabilidade do tegumento como causa da dormência e apontam varias sugestôes de tratamentos pré-germinativos (Moreira e Moreira, 1996; Cruz et al., 2001a; Ramos e Varela, 2003). Alguns ressaltam como métodos de superação da dormência a escarificaçáo química, ou mecânica (com desponte e lixamento), a estratificaçáo, o choque de temperatura e a queima do tegumento com pirógrafo (Souza e Silva, 1998; CATIE, 1999; Souza et al., 2000; Cruz et al., 2001b; Smiderle e Sousa, 2003). Todos esses tratamentos apresentam vantagens e desvantagens, de modo que, cada um deles deve ser estudado, levando-se em conta, também, a sua praticidade de execuçáo. Assim, o objetivo deste trabalho foi avaliar os efeitos da aplicação de diferentes tratamentos pré-germinativos de escarificação mecânica e de uso do calor (seco e úmido) sobre a germinação de sementes de visgueiro-do-igapó (P. discolor).

\section{MATERIAL E MÉTODOS}

As sementes utilizadas neste trabalho foram provenientes de frutos de matrizes localizadas na Reserva de Desenvolvimento Sustentável do Tupé (0302'51" S, 60¹5'21" W e altitude média $20 \mathrm{~m}$ a.n.m.), situada na margem esquerda do Rio Negro, a Oeste de Manaus, distante aproximadamente $25 \mathrm{~km}$ em linha reta do centro da cidade. Esta pesquisa foi conduzida no Laboratório de Sementes da Coordenação de Pesquisas em Ciências Agronômicas (CPCA) do Instituto Nacional de Pesquisas da Amazônia (INPA) em Manaus (AM), onde foram desenvolvidos dois ensaios, independentes, como seguem.

\section{TRATAMENTO PRÉ-GERMINATIVO COM ESCARIFICAÇÃO MECÂNICA}

Após secagem prévia dos frutos (vagem), sob condiçóes ambiente, foi feita a extração das sementes com auxílio de tesoura de poda e, em seguida, colocadas em solução de hipoclorito de cálcio $\left(\mathrm{CaOCl}_{2}\right)$ a $1 \%$ durante 3 horas, a fim de facilitar a retirada da goma que se encontrava aderida às mesmas. Depois, as sementes foram lavadas em água corrente, secas sob condição ambiente (temperatura $26-28^{\circ} \mathrm{C}$; U.R. $82 \%$ ), acondicionadas em frascos de vidro com tampa (após eliminação das perfuradas por insetos e mal formadas) e armazenadas em câmara com temperatura de $20^{\circ} \mathrm{C}$, durante seis meses.

As sementes foram submetidas aos seguintes tratamentos pré-germinativos: T1 - testemunha (sem pré-tratamento); T2 - desponte no lado distal da semente, ou lado oposto ao da emissão da raiz primária; T3 - desponte no lado proximal, ou região do hilo; T4 - desponte no lado distal e proximal, ao mesmo tempo; T5 - lixamento no lado distal; T6 - lixamento no lado proximal; T7 - lixamento nos lados distal e proximal da semente; T8 - perfuração do tegumento, com ferro-de-solda, na regiáo mediana aplanada da semente; e T9 - perfuraçáo do tegumento com pirógrafo, na regiáo mediana aplanada da semente. Os despontes foram feitos com cortador-deunha, eliminando o tegumento, sem afetar o cotilédone; o lixamento foi feito sobre lixa d'água número 220, durante aproximadamente três a quatro segundos; foi utilizado ferro-de-solda de ponta fina de $30 \mathrm{~W}$ aplicada durante aproximadamente três a quatro segundos; a extremidade aquecida do pirógrafo foi aplicada durante três segundos. Em seguida, as sementes foram semeadas em papel-toalha, umedecido até completa saturaçáo, acondicionado em sacos de plástico fechados e mantidos em câmaras de germinação com temperatura de $25^{\circ} \mathrm{C}$ e fotoperíodo de 12 horas. A germinação foi considerada a partir da protrusão da raiz primária. O acompanhamento foi diário pelo período de 
uma semana. A partir da contagem de germinação foram estimados: a germinação (em percentagem), o tempo médio de germinação (Edwards, 1934) e o índice de velocidade de germinação (Maguire, 1962).

Visando avaliar a embebição das sementes (absorção de água), antes da semeadura, cada parcela dos diferentes tratamentos pré-germinativos, foi avaliada quanto à massa, $\mathrm{o}$ que se repetiu, depois da semeadura, a cada três horas, durante as primeiras 12 horas, e em seguida, a cada 12 até completar a germinação de todas as sementes. Também, antecedendo a semeadura e utilizando sementes intactas, foi determinado o grau de umidade, utilizando-se duas repetiçóes de 20 sementes, cortadas ao meio, que permaneceram em estufa a $105+/-3{ }^{\circ} \mathrm{C}$, durante 24 horas (BRASIL, 1992).

$\mathrm{O}$ delineamento experimental utilizado foi o inteiramente casualizado, com nove tratamentos, cada um com quatro repetiçôes de 25 sementes. Após análise de variância, as médias dos tratamentos foram comparadas pelo teste de Tukey a 5\% de probabilidade.

\section{TRATAMENTO PRÉ-GERMINATIVO COM CALOR SECO E ÚMIDO}

Após extração das sementes, da mesma forma como no experimento anterior, estas foram submersas em água, durante 24 horas, para facilitar a retirada da goma. Em seguida, foram lavadas em água corrente, secas sob condiçôes ambientes e eliminadas as que apresentavam perfuraçôes de insetos e mal formadas. Então, foram armazenadas em frasco de vidro lacrado, em câmara com temperatura de $20^{\circ} \mathrm{C}$, durante dois meses.

Como tratamento pré-germinativo, as sementes foram acondicionadas em latas de alumínio lacradas com fita adesiva com metade do número de recipientes sem nada, além das sementes, e a outra metade contendo água, o equivalente a três vezes o volume das sementes. Assim, foram colocadas em estufas, nas temperaturas de $40^{\circ} \mathrm{C}, 50^{\circ} \mathrm{C}, 60^{\circ} \mathrm{C}$ e $70^{\circ} \mathrm{C}$, onde permaneceram pelos períodos de 6, 16, 24, 30 e 48 horas. Depois, as sementes foram semeadas sobre papeltoalha, umedecidos até completa saturação, acondicionados em sacos de plástico fechados e mantidos em câmaras de germinação, com temperatura de $25^{\circ} \mathrm{C}$ e fotoperíodo de 12 horas. $\mathrm{O}$ acompanhamento da germinação foi a cada dois dias, identificando-se, em cada parcela, o número de sementes que apresentavam protrusão da raiz primária.

O delineamento experimental utilizado foi o inteiramente casualizado, em esquema fatorial 2 (calor: seco e úmido) x 4 (temperatura: $40^{\circ} \mathrm{C}, 50^{\circ} \mathrm{C}, 60^{\circ} \mathrm{C}$ e $70^{\circ} \mathrm{C}$ ) x 5 (período de condicionamento: $6,16,24,30$ e 48 horas), com três repetiçóes de 25 sementes. Os resultados obtidos foram submetidos à análise de variância e as médias dos tratamentos foram comparadas entre si pelo teste de Tukey, a 5\% de probabilidade.

\section{RESULTADOS E DISCUSSÃO}

\section{TRATAMENTO PRÉ-GERMINATIVO COM ESCARIFICAÇÃO MECÂNICA}

O teor de água inicial das sementes foi de $9,8 \%$ e comprovou-se a impermeabilidade do tegumento de sementes de $P$. discolor, pois, somente as sementes que foram submetidas aos tratamentos de escarificação mecânica tiveram embebição (Figura 1A). Este processo foi mais rápido quando as sementes foram tratadas, ao mesmo tempo, nas duas extremidades (proximal e distal), tanto com desponte quanto com lixamento. Num segundo grupo, com velocidades de embebição um pouco menor, ficou as sementes que sofreram desponte ou lixamento em uma das regióes (proximal ou distal), seguidas das que foram tratadas com pirógrafo e, por fim, as que foram perfuradas com ferro-de-solda. Coutinho e Struffaldi (1971), após escarificação em ácido sulfúrico concentrado (15') e colocação das sementes de $P$. discolor diretamente em água, obtiveram uma embebição de 148\% em 24 horas. No presente trabalho, com a embebição em papel-toalha umedecido, valor equivalente só foi alcançado a partir de 3 dias.

De modo geral, e principalmente onde absorção de água foi mais rápida (desponte e lixamento nas duas extremidades), a curva de embebição (Figura 1A) se comportou de modo semelhante a que é apresentada por Castro e Hilhorst (2004): inicialmente as sementes tiveram uma elevada embebição, a chamada Fase I; no momento seguinte a absorção de água diminuiu, em relação à fase anterior (Fase II); por último, a embebição voltou a ser a elevada (Fase III) e parte deste aumento foi devido ao crescimento da raiz primária.

Os tratamentos escarificadores aplicados nas sementes favoreceram a superação da dormência em diferentes graus, quando comparado às sementes sem pré-tratamento (Figura $1 \mathrm{~B}$ e Tabela 1). Na testemunha (sem pré-tratamento) não houve germinação, corroborando com o fato de não ter ocorrido embebição. Com exceção da utilização do ferrode-solda, os demais pré-tratamentos tiveram excelente desempenho quanto ao percentual final de germinação, até os sete dias após a semeadura. Contudo, levando em conta os índices de vigor (índice de velocidade de germinação - IVG e tempo médio de germinação - TMG), os melhores resultados foram obtidos com desponte proximal, desponte proximal mais distal, lixamento proximal e lixamento proximal mais distal. Estes resultados demonstraram a possibilidade de utilização da escarificação no lado proximal, ou região do hilo, sem agredir o embriāo, e de favorecimento da germinação das sementes, discordando da opiniáo de alguns autores, como Souza e Silva (1998). 

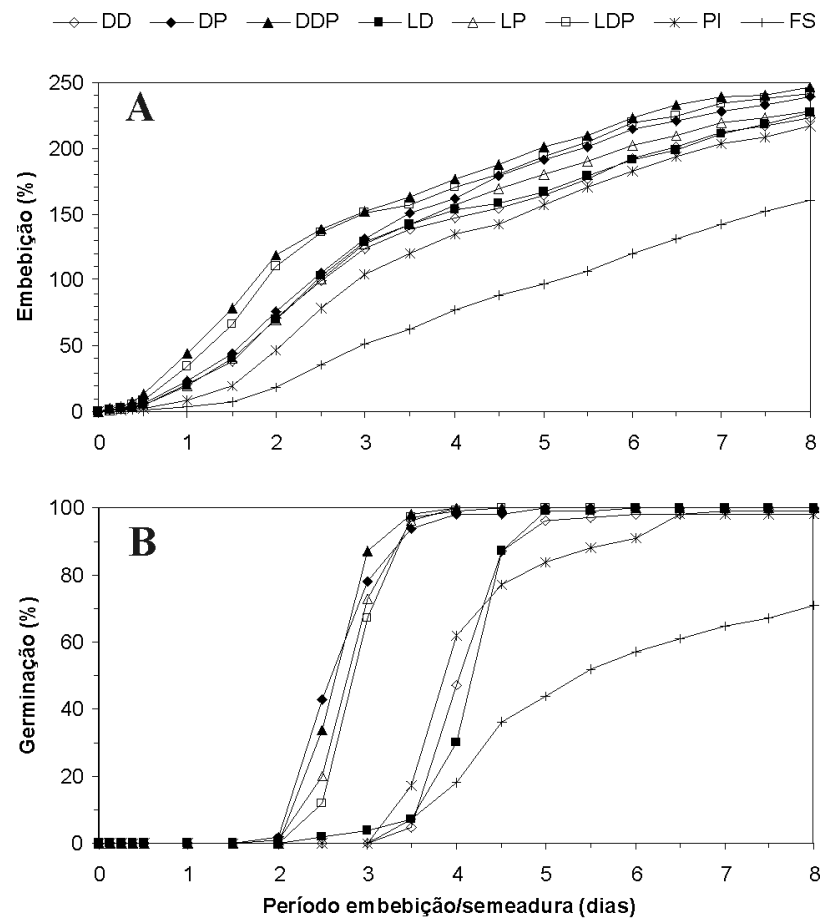

Figura 1 - Embebição (A) e germinação acumulada (B) de sementes de visgueiro-do-igapó (P. discolor) em função do pré-tratamento aplicado: DD - desponte na região distal da semente; DP - desponte na região proximal; DDP - desponte nas regiões distal e proximal; LD - lixamento na região distal LP - lixamento na região proximal; LDP - lixamento nas regiões distal e proximal; $\mathrm{PI}$ - perfuração com pirógrafo na porção média aplanada da semente; e FS - perfuração com ferro-de-solda na porção média aplanada.

Tabela 1 - Germinação, índice de velocidade de germinação (IVG) e tempo médio de germinação (TMG), referente a sementes de visgueiro-do-igapó (P. discolor) submetidas a diferentes pré-tratamentos de escarificação mecânica.

\begin{tabular}{lccc}
\hline Tratamentos & Germinação (\%) & IVG & TMG (horas) \\
\hline Testemunha & $0,0 \mathrm{c}$ & $0,000 \mathrm{e}$ & - \\
\hline Desponte distal & $99,2 \mathrm{a}$ & $0,963 \mathrm{c}$ & $104 \mathrm{~b}$ \\
Desponte proximal & $99,5 \mathrm{a}$ & $1,460 \mathrm{a}$ & $70 \mathrm{a}$ \\
Desponte distal e proximal & $99,5 \mathrm{a}$ & $1,455 \mathrm{a}$ & $70 \mathrm{a}$ \\
Lixamento distal & $99,5 \mathrm{a}$ & $0,971 \mathrm{c}$ & $105 \mathrm{~b}$ \\
Lixamento proximal & $99,5 \mathrm{a}$ & $1,389 \mathrm{ab}$ & $73 \mathrm{a}$ \\
Lixamento distal e proximal & $99,5 \mathrm{a}$ & $1,351 \mathrm{~b}$ & $75 \mathrm{a}$ \\
Pirógrafo & $98,6 \mathrm{a}$ & $0,964 \mathrm{c}$ & $105 \mathrm{~b}$ \\
Ferro-de-solda & $71,1 \mathrm{~b}$ & $0,608 \mathrm{~d}$ & $123 \mathrm{c}$ \\
C.V. (\%) & 4,0 & 3,9 & 3,3 \\
\hline
\end{tabular}

Médias seguidas da mesma letra não diferem entre si pelo teste de Tukey ao nível de $5 \%$ de probabilidade.

O pré-tratamento com pirógrafo, apesar de ter apresentado menor desempenho quanto as variáveis de vigor (IVG e TMG), demonstrou ser uma boa opção para as sementes de visgueiro-do-igapó, considerando que é um método de fácil aplicaçấo, principalmente quando se tratar de um lote de sementes maior. No tratamento pré-germinativo com ferro- de-solda, a menor germinação pode ser atribuída à menor absorçáo de água, provavelmente, em decorrência da pouca pressão exercida sobre as sementes com este equipamento, durante a perfuração (ou queima) do tegumento, ou ainda, pouco tempo empregado nesta operaçáo. Esse resultado sugere mais estudos acerca da intensidade e da duraçáo do processo de perfuraçáo do tegumento deste tipo de semente.

Vários estudos sobre dormência em sementes de leguminosas têm demonstrado o efeito positivo de tratamentos pré-germinativos com escarificação mecânica. Souza e Silva (1998) obtiveram bons resultados de germinação de Cassia moschata (83\%) e Entada polystachya (90\%) após a escarificação, com esmeril elétrico, na porção distal das sementes. Smiderle e Sousa (2003) registraram $79 \%$ de germinaçâo para paricarana (Bowdichia virgilioides) utilizando lixa d'água por 1 minuto. Resultados semelhantes foram obtidos por Cruz et al. (2001b) com jatobá-curuba (Hymenaea intermedia); Souza e Varela (1989) com faveira-orelha-de-macaco (Enterolobium schomburgkii); Souza et al. (1994) com muirajuba (Apuleia leiocarpa); e Cruz et al. (2001a) com Parkia nitida.

\section{TRATAMENTO PRÉ-GERMINATIVO COM CALOR SECO E ÚMIDO}

Após um mês de acompanhamento deste experimento, verificou-se que nenhum dos tratamentos pré-germinativos aplicados foi efetivo para superar a dormência e promover a germinação das sementes de $P$. discolor. Devido a isto, e com a finalidade de avaliar os efeitos dos pré-tratamentos com calor sobre a viabilidade das sementes, foi feito o desponte na porção distal das sementes em todos os tratamentos. Entáo, estas, foram re-semeadas e feita avaliação da germinação por mais sete dias. Assim, constatou-se que a viabilidade das sementes foi afetada de maneira distinta em função dos pré-tratamentos aplicados (Tabela 2 e 3 ).

Tabela 2 - Germinação e índice de velocidade de germinação (IVG) de sementes de visgueiro-do-igapó (P. discolor) em função do tipo de calor e do período de condicionamento utilizados como tratamentos pré-germinativos.

\begin{tabular}{lccc}
\hline Calor & $\begin{array}{c}\text { Período de } \\
\text { condicionamento } \\
\text { (horas) }\end{array}$ & Germinação(\%) & IVG \\
\hline \multirow{3}{*}{ Úmido } & 6 & $85,9 \mathrm{a}$ & $15,777 \mathrm{a}$ \\
& 16 & $86,4 \mathrm{a}$ & $15,849 \mathrm{a}$ \\
& 24 & $72,1 \mathrm{~b}$ & $13,028 \mathrm{~b}$ \\
& 30 & $75,8 \mathrm{ab}$ & $13,173 \mathrm{~b}$ \\
\hline \multirow{3}{*}{ Seco } & 48 & $73,8 \mathrm{~b}$ & $13,154 \mathrm{~b}$ \\
& 6 & $93,1 \mathrm{a}$ & 15,653 \\
& 16 & $81,7 \mathrm{~b}$ & 13,958 \\
\hline C.V. (\%) & 24 & $85,6 \mathrm{ab}$ & 14,067 \\
\hline
\end{tabular}

Médias seguidas da mesma letra não diferem entre si pelo teste de Tukey ao nível de $5 \%$ de probabilidade. 
Tabela 3 - Germinação, índice de velocidade de germinação (IVG) e tempo médio de germinação (TMG) de sementes de visgueiro-do-igapó (Parkia discolor) em função da temperatura e do período de condicionamento utilizado como tratamentos pré-germinativos.

\begin{tabular}{|c|c|c|c|c|}
\hline Temperatura $\left({ }^{\circ} \mathrm{C}\right)$ & $\begin{array}{c}\text { Período de } \\
\text { condicionamento } \\
\text { (horas) }\end{array}$ & $\begin{array}{c}\text { Germinação } \\
(\%)\end{array}$ & IVG & TMG \\
\hline \multirow{5}{*}{40} & 6 & 95,6 & 18,242 & 5,1 \\
\hline & 16 & 98,2 & 20,496 & 5,3 \\
\hline & 24 & 98,5 & 18,242 & 5,3 \\
\hline & 30 & 97,2 & 18,020 & 5,4 \\
\hline & 48 & 98,6 & 18,552 & 5,3 \\
\hline \multirow{5}{*}{50} & 6 & 96,1 & 18,113 & 5,2 \\
\hline & 16 & 95,3 & 18,072 & 5,3 \\
\hline & 24 & 97,3 & 17,993 & 5,4 \\
\hline & 30 & 97,1 & 17,800 & 5,3 \\
\hline & 48 & 99,9 & 18,977 & 5,3 \\
\hline \multirow{5}{*}{60} & 6 & 99,6 & 18,280 & 5,5 \\
\hline & 16 & 99,8 & 18,748 & 5,4 \\
\hline & 24 & 97,2 & 17,537 & 5,5 \\
\hline & 30 & 98,1 & 18,360 & 5,3 \\
\hline & 48 & 93,2 & 16,737 & 5,4 \\
\hline \multirow{5}{*}{70} & 6 & $47,5 \mathrm{a}$ & $8,278 a$ & $5,8 \mathrm{a}$ \\
\hline & 16 & $13,2 \mathrm{~b}$ & $2,298 \mathrm{~b}$ & $5,8 \mathrm{a}$ \\
\hline & 24 & $2,9 \mathrm{c}$ & $0,418 b$ & $3,2 b$ \\
\hline & 30 & $4,1 \mathrm{bc}$ & $0,812 b$ & $3,3 b$ \\
\hline & 48 & $0,9 \mathrm{c}$ & $0,000 \mathrm{~b}$ & - \\
\hline C.V. (\%) & - & 11,2 & 10,9 & 23,6 \\
\hline
\end{tabular}

Médias seguidas da mesma letra não diferem entre si pelo teste de Tukey ao nível de $5 \%$ de probabilidade.

A germinação e o índice de velocidade de germinação (IVG) apresentaram efeito de interação significativa entre os fatores tipo de calor versus período de condicionamento; o tempo médio de germinação (TMG) não foi influenciado pelo tipo de calor, bem como, para esta mesma variável, o tipo de calor não apresentou efeito de interaçóes com os demais fatores. O calor úmido, de certo modo, causou maior comprometimento da viabilidade (germinação) e do vigor (IVG) das sementes e, independente do tipo de calor, estas mesmas variáveis decresceram à medida que se elevou o período de condicionamento (Tabela 2).

A germinação, o IVG e o TMG apresentaram efeito de interação entre os fatores temperatura versus período de condicionamento. Sob as temperaturas de $40^{\circ} \mathrm{C}, 50^{\circ} \mathrm{C}$ e $60^{\circ} \mathrm{C}$, a germinação, o IVG e o TMG não foram afetados em funçáo dos diferentes períodos de condicionamento (Tabela $3)$ : as sementes se mantiveram viáveis. Por outro lado, sob $70^{\circ} \mathrm{C}$, houve comprometimento da viabilidade e do vigor das sementes em todos os períodos, o que se agravou com o aumento do tempo de condicionamento.
Wutke et al. (1995) observaram que, em sementes de mucuna-preta (Mucuna aterrima), a impermeabilidade do tegumento foi superada com o uso do calor seco $\left(55^{\circ} \mathrm{C}\right)$, sendo mais efetivo os períodos de exposição entre 16 e 24 horas. As temperaturas de $60^{\circ} \mathrm{C}$ e $70^{\circ} \mathrm{C}$, aplicadas durante 15 horas, foram mais eficientes na superação da dormência de sementes de Stylosanthes macrocephala e S. capitata, respectivamente (Alencar et al., 2009). Por outro lado, nem sempre o tratamento pré-germinativo com calor oferece resultados favoráveis quanto à superaçáo da dormência em sementes de leguminosas. Em sementes de Desmodium incanum, Garcia e Baseggio (1999) não obtiveram resultados favoráveis com utilização do calor seco e do calor úmido como tratamentos pré-germinativos. Sob condiçóes de elevada umidade relativa $(100 \%)$, as temperaturas de $50^{\circ} \mathrm{C}$ e $60^{\circ} \mathrm{C}$, durante os períodos de 48 e 72 horas, mostraram-se inadequadas como tratamentos pré-germinativos em sementes de Adenanthera pavonina (Fanti e Perez, 1999). Em estudo com Anadenanthera colubrina, Garcia et al. (2004) observaram redução na germinação quando as sementes foram submetidas à temperatura de $40^{\circ} \mathrm{C}$ durante 24, 48, 72 e 96 horas, com UR de 95\%. Vieira $e t$ al. (1994) mencionam que as alteraçóes degenerativas que ocorrem nas estruturas internas da semente, por ocasião da temperatura e período de condicionamento, promovem um descontrole no metabolismo e nas trocas de água e de solutos entre as células e o meio exterior, determinando a queda da viabilidade das sementes.

\section{CONCLUSÕES}

A dormência em sementes de visgueiro-do-igapó é causada pela impermeabilidade do tegumento à água e pode ser superada pela escarificação mecânica (desponte, ou lixamento, na porção proximal e porçôes proximal e distal, ao mesmo tempo);

O pré-tratamento com pirógrafo pode ser considerado um método alternativo para lotes maiores de sementes, por ser fácil e de aplicação rápida;

Os pré-tratamentos com calor (úmido e seco), sob diferentes temperaturas $\left(40^{\circ} \mathrm{C}, 50^{\circ} \mathrm{C}, 60^{\circ} \mathrm{C} \mathrm{e} 70^{\circ} \mathrm{C}\right)$ e períodos de condicionamento $(6,16,24,30$ e 48 horas) não superaram a dormência de sementes de Parkia discolor.

\section{AGRADECIMENTOS}

Agradecemos a Fundaçáo de Amparo à Pesquisa do Estado do Amazonas (FAPEAM), pelo apoio financeiro à pesquisa e pela bolsa concedida à primeira autora, e ao projeto Biotupé que facilitou a obtenção de sementes. 


\section{BIBLIOGRAFIA CITADA}

Alencar, K.M.C.; Laura, V.A.; Rodrigues, A.P.D.C.; Resende, R.M.S. 2009. Tratamento térmico para superação da dormência em sementes de Stylosanthes SW. (Fabaceae Papilionoideae). Revista Brasileira de Sementes, 31: 164-170.

BRASIL. 1992. Ministério da Agricultura e Reforma Agrária. Regras para análise de sementes, Brasília, DF: SNDA/DNDV/CLAV. $365 \mathrm{pp}$

Castro, R.D.C.; Hilhorst, H.W.M. 2004. Embebição e reativação do metabolismo, p. 149-162. In: Ferreira, A.G.; Borghetti, F. Germinação: do básico ao aplicado. Porto Alegre: Artmed.

CATIE. 1999. Técnicas para la escarificación de semillas forestales. Turrialba: Centro Agronómico Tropical de Investigación y Enseńanza. Proyecto de Semillas Forestales. (Serie Técnica, 36). $60 \mathrm{pp}$.

Cavada, B.S.; Madeira, S.V.F.; Calvete, J.J.; Souza, L.A.G.; Bomfim, L.R.; Dantas, A.R.; Lopes, M.C.; Grangeiro, T.B.; Freitas, B.T.; Pinto, V.P.T.; Leite, K.B.; Ramos, M.V. 2000. Purification, Chemical and imunochemical properties of a new lectin from Mimosoideae (Parkia discolor). Preparative Biochemistry and Biotechnology, 30: 271-280.

Coutinho, L.M.; Struffaldi, Y. 1971. Observações sobre a germinação das sementes e o crescimento das plântulas de uma leguminosa da mata amazônica de igapó (Parkia auriculata Spruce Mss.). Phyton, 28: 149-159.

Cruz, E.D.; Carvalho, J.E.U.; Leão, N.V.M. 2001. Métodos para a superação da dormência e biometria de frutos e sementes de Parkia nitida Miquel. (Leguminosae - Mimosoideae). Acta Amazonica, 31: 167-177.

Cruz, E.D.; Martins, F.O.; Carvalho, J.E.U. 2001. Biometria de frutos e sementes e germinação de jatobá-curuba (Hymenaea intermedia Ducke, Leguminosae - Caesalpinioideae). Revista Brasileira de Botânica, 24: 161-165.

Edwards, I. 1934. Relations of germinating so beans to temperature and length of incubations time. Plant Physiology, 9: 1-30.

Fanti, S.C.; Perez, S.C.J.G.A. 1999. Influência do substrato e do envelhecimento acelerado na germinação de olho-de-dragão (Adenanthera pavonina L. - Fabaceae). Revista Brasileira de Sementes, 21: 135-141.

Garcia, E.N.; Baseggio, J. 1999. Poder germinativo de sementes de Desmodium incanum DC. (Leguminosae). Revista Brasileira de Agrociência, 5: 199-202.

Garcia, L.C.; Nogueira, A.C.; Abreu, D.C.A. 2004. Influência do envelhecimento acelerado no vigor de sementes de Anadenanthera colubrina (Vellozo) Brenan - Mimosaceae. Ciência Florestal, 14: 85-90.
Hopkins, H.C.F. 1986. Parkia (Leguminosae: Mimosoideae). Flora Neotropica. Monograph, 43: 74-77.

Maguire, J.D. 1962. Speed of germination-aid in selection and evaluation for seedling emergence and vigor. Crop Science, 2: 176-177.

Moreira, F.M.S.; Moreira, F.W. 1996. Características da germinação de sementes de 64 espécies de leguminosas florestais nativas da Amazônia, em condições de viveiro. Acta Amazonica, 26: 3-16.

Ramos, M.B.P.; Varela, V.P. 2003. Efeito da temperatura e do substrato sobre a germinação de sementes de visgueiro do igapó (Parkia discolor Benth.) Leguminosae, Mimosoideae. Revista de Ciências Agrárias, 39: 135-143.

Smiderle, O.J.; Sousa, R.C.P. 2003. Dormência em sementes de paricarana (Bowdichia virgilioides Kunth - FabaceaePapilionidae). Revista Brasileira de Sementes, 25: 48-52.

Souza, L.A.G.; Albertino, S.M.F.; Silva, M.F.; Silva, J.F. 2000. Superação da dormência de sementes de oito espécies de leguminosas herbáceas submetidas a tratamentos prégerminativos. Revista da Universidade do Amazonas, série ciências agrárias, 9: 1-23.

Souza, L.A.G.; Silva, M.F. 1998. Tratamentos escarificadores em sementes duras de sete leguminosas nativas da ilha de Maracá, Roraima, Brasil. Boletim do Museu Paraense Emílio Goeldi, série botânica, 14: 11-32.

Souza, L.A.G.; Silva, M.F. 2002. Levantamento das leguminosas do arquipélago das Anavilhanas, baixo rio negro, Amazonas. Boletim do Museu Paraense Emilio Goeldi, 18: 3-35.

Souza, L.A.G.; Silva, M.F.; Moreira, F.W. 1994. Capacidade de nodulação de 100 leguminosas da região Amazônica. Acta Amazonica, 24: 9-18.

Souza, S.G.A.; Varela, V.P. 1989. Tratamentos pré-germinativos em sementes de faveira orelha de macaco (Enterolobium schomburgkii Benth.). Acta Amazonica, 19: 19-26.

Vieira, R.D.; Carvalho, N.M.; Sader, R. 1994. Teste de vigor e suas possibilidades de uso, p. 31-47. In: Vieira, R.D.; Carvalho, N.M. Teste de vigor em sementes. Jaboticabal : UNEP/UNESP.

Wutke, E.B.; Maeda, J.A.; Pio, R.M. 1995. Superação da dormência de sementes de mucuna-preta pela utilizaçáo de "calor seco". Scientia Agricola, 52: 482-490.

Recebido em 01/12/2008

Aceito em 03/10/2009 